\title{
EFFECT OF HEPATIC DYSFUNCTION ON CIRCULATING LEVELS OF SULFOBROMOPHTHALEIN AND ITS METABOLITES *
}

\author{
By JOHN V. CARBONE, GEROLD M. GRODSKY AND VIRGINIA HJELTE \\ (From the Gastrointestinal Laboratory, San Irancisco Gencral Hospital [Unizersity of Cali- \\ formia Service], the Metabolic Unit for Research in Arthritis and Allied Diseases, \\ and the Department of Medicine, University of California School of Medicine, \\ San Francisco, Calif.)
}

(Submitted for publication June 8, 1959; accepted July 23, 1959)

Sulfobromophthalein (BSP) clearance has proved a sensitive index of hepatic function. Although dosage, sampling intervals and techniques of measurement have been modified (1-4), the procedure remains essentially as originally described $(5,6)$. Basically it consists of the intravenous injection of a standard amount of BSP and determination of residual BSP in the plasma from blood samples collected at prescribed intervals.

Since clearance of BSP is decreased both in hepatocellular dysfunction and biliary obstruction, its determination is of limited usefulness in differentiating these two conditions. Recent studies, however, have shown that $\mathrm{BSP}$ is conjugated in the liver and excreted primarily as conjugates into the bile and to a lesser extent into the urine (711). Chemical analysis indicates that the dye is conjugated with cysteine and possibly with the peptide, glutathione (12). These metabolites are colorimetrically indistinguishable from free BSP. The demonstration that sulfobromophthalein is conjugated by the liver suggests the following possibilities: 1) where uptake or hepatic conjugation of BSP is impaired due to parenchymal dysfunction, the circulating dye should remain in the unconjugated form; 2) in biliary obstruction, where conjugation of the dye proceeds normally but secretion from the liver is impaired, increasing amounts of conjugated dye should appear in the blood. If such is true, the determination of the metabolized BSP, in addition to total BSP, in serum might serve to distinguish impairment of uptake or conjugation from intrahepatic or extrahepatic biliary obstruction.

In this study the levels of free and conjugated

\footnotetext{
* Supported by a grant (A-2455) from the National Institutes of Health, United States Public Health Service, Bethesda, Md.
}

BSP were investigated in sera and urine from normal subjects and patients with hepatic disease.

\section{SUBJECTS AND METHODS}

The 87 subjects selected for study consisted of $17 \mathrm{pa}$ tients with normal liver function, 10 patients in whom liver function tests and clinical work-up (including liver biopsy when feasible) indicated viral hepatitis, 33 patients with portal cirrhosis and varying degrees of hepatic decompensation, 10 patients with extrahepatic obstruction as indicated by liver function studies and confirmed by surgical exploration, and 17 patients initially with normal liver function who were given methyltestosterone ( $67 \mathrm{mg}$. per day) for 14 days.

The following liver function tests were carried out in each group : total serum protein and albumin (13) ; alkaline phosphatase (14) (upper limit of normal in our laboratory is 8 units); one minute and total bilirubin (15) and 45 minute BSP retention (16). In addition, serum glutamic oxalacetic transaminase levels (17) were determined in the subjects treated with methyltestosterone.

The circulating level of BSP metabolites was determined in fasting subjects as follows. Commercial BSP ( $5 \mathrm{mg}$. per $\mathrm{Kg}$. body weight) was injected intravenously. Blood was drawn from the opposite arm at specific intervals. The BSP pigments were extracted from $2 \mathrm{ml}$. of serum ${ }^{1}$ with $6 \mathrm{ml}$. of acetone. Less than 3 per cent of the total pigment remained in the protein fraction of sera containing high concentrations of the metabolites. The acetone extract was taken to dryness in vacuo and redissolved in water (approximately $0.2 \mathrm{ml}$. per ml. of initial serum). A $0.2 \mathrm{ml}$. aliquot of the solution was chromatographed on Whatman $3 \mathrm{MM}$ paper in an ascending system employing tert-butanol-water $(1.73: 1$ $\mathrm{v} / \mathrm{v})$ for six to 15 hours. The BSP bands were developed with ammonia fumes. Both major metabolite bands ( $R_{f}$ approximately 0.65 and 0.23 ) were cut from the strip, pooled and macerated in $25 \mathrm{ml}$. of $0.05 \mathrm{~N} \mathrm{NaOH}$. The mixture was centrifuged for 10 minutes to remove the paper pulp. Duplicate samples of $6 \mathrm{ml}$. of the supernatant were transferred to an Evelyn cuvette and read against a blank of $0.05 \mathrm{~N} \mathrm{NaOH}$ at 565 and $620 \mathrm{~m} \mu$. The unconjugated BSP band ( $R_{\mathfrak{f}}$ approximately 0.88 ) was similarly extracted from the paper and quantified.

${ }^{1}$ Serum could be stored at $-20^{\circ} \mathrm{C}$. for several months without affecting the results of the tests. 

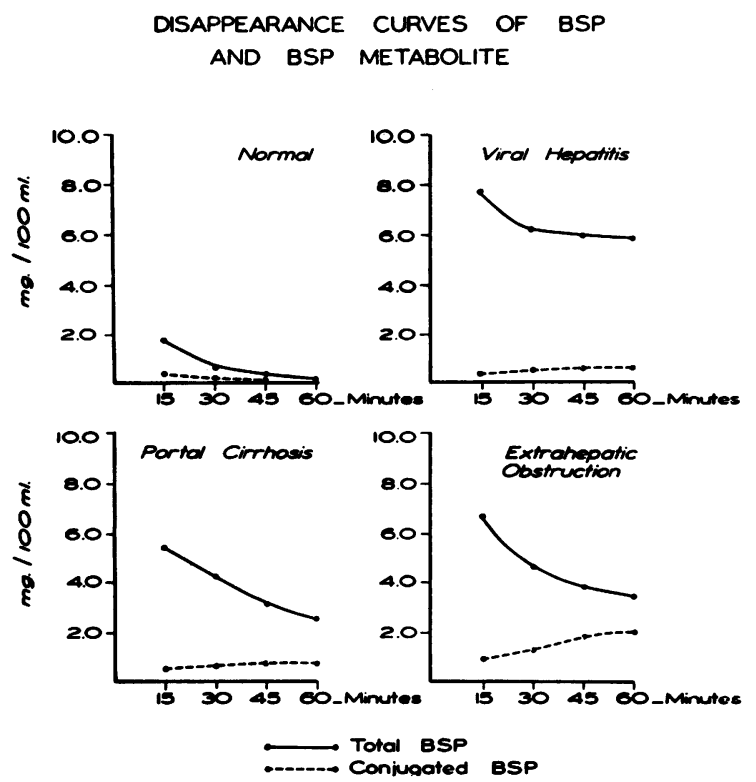

Fig. 1. Comparison of Total and Conjugated SulFOBRomophthalein FROM NORMal SUbJECTS AND From Patients with Viral Hepatitis, Portal Cirrhosis and Extrahepatic Obstruction

The percentage of BSP conjugate was calculated according to the formulas :

O.D.565 - 1.3 O.D.620 (unknown)

O.D. 565 - 1.3 O.D.620 (standard)

$X$ concentration of standard

$=\mathrm{mg} . \mathrm{BSP}$ per $100 \mathrm{ml}$. and

$\frac{\text { BSP conjugate }}{\text { free BSP }+ \text { BSP conjugate }} \times 100$

$=$ per cent $\mathrm{BSP}$ conjugate. ${ }^{2}$

The standard deviation obtained after duplicate determinations on 15 different serum samples was 2.1 per cent.

Renal excretion of free and conjugated BSP was determined in several patients from each group as follows. Urine was collected for two hours after injection of the dye. A $30 \mathrm{ml}$. aliquot was taken to dryness in a rotary evaporator at $40^{\circ} \mathrm{C}$. The concentrate was taken up in a minimum volume of distilled water and extracted with three volumes of acetone. The acetone extract was chromatographed and the BSP bands were quantitatively evaluated as described for the serum extracts.

\section{RESULTS}

\section{Rate of appearance of BSP and its metabolites}

To establish optimal sampling intervals, BSP retention was measured in five patients each from

\footnotetext{
2 This calculation assumes that the free and conjugated dye have the same molecular extinction coefficient. Accurate determination of the constant for the conjugates must await their availability in crystalline, pure form.
}

the groups with normal liver function, cirrhosis, acute viral hepatitis and extrahepatic biliary tract obstruction. Measurements were made on blood samples drawn at four 15 minute intervals after injection of the dye (Figure 1).

In the normal subjects BSP was cleared rapidly from the circulation. At the end of 45 and 60 minutes only traces of free and conjugated dye were present in the serum. In the patients with hepatitis, although large amounts of the free dye were retained, the serum contained only small quantities of the conjugated form. In the patients with cirrhosis, the retention of dye was not so pronounced and the amount of conjugated dye was somewhat greater than that found in the patients with viral hepatitis. In the patients with extrahepatic obstruction, however, the amount of conjugated dye increased progressively throughout the test period and was significantly greater than in the other three groups.

The 45 and 60 minute intervals for sampling levels of free and conjugated dye were equally adequate for distinguishing the various types of hepatic dysfunction. Since the major experience in this laboratory has been with the 45 minute BSP test (16), this sampling time was selected for use in this study.

\section{Results of liver function tests}

Viral hepatitis (Table I). In the patients with viral hepatitis, total BSP retention 45 minutes after injection of the dye was $56.4 \pm 2.4$ per cent. $^{3}$ Of this high percentage of retained dye only $8.0 \pm 2.3$ per cent was in the conjugated form. All of the subjects were jaundiced. The mean total serum bilirubin concentration was $11.1 \mathrm{mg}$. per $100 \mathrm{ml}$. of serum, of which 47.4 per cent was direct bilirubin (presumably bilirubin glucuronide).

Portal cirrhosis (Table I). In this group total $\mathrm{BSP}$ retention averaged $31.8 \pm 2.8$ per cent. Of the circulating dye only $16.9 \pm 1.5$ per cent was in the form of metabolites. Mild jaundice was generally observed. The mean total serum bilirubin concentration was $3.8 \pm 1.0 \mathrm{mg}$. per $100 \mathrm{ml}$., of which 39.3 per cent was direct bilirubin.

Extrahepatic obstruction (Table II). In the patients with extrahepatic obstruction, total BSP

\footnotetext{
3 Mean plus or minus standard error.
} 
retention was elevated $(40.3 \pm 5.0$ per cent $)$. In these subjects, however, almost one-half the total circulating BSP (41.1 \pm 6.9 per cent) was in the metabolized form. The mean total bilirubin was consistently elevated. Direct bilirubin comprised 36.2 per cent of the total, a value similar to those observed in the first two groups. Serum alkaline phosphatase was notably elevated $(32.3 \pm 3.4$ units per $100 \mathrm{ml}$.).

Intrahepatic obstruction (Table II). In the subjects given methyltestosterone the mean BSP retention was moderately high $(19.6 \pm 5.0$ per cent). As in the group with extrahepatic obstruction a large proportion of the circulating dye

TABLE I

Results of liver function tests in patients with viral hepatitis and portal cirrhosis

\begin{tabular}{|c|c|c|c|c|c|c|c|c|c|}
\hline \multirow[b]{2}{*}{ Patient } & \multirow[b]{2}{*}{ Age } & \multirow[b]{2}{*}{ Sex } & \multirow{2}{*}{$\begin{array}{c}\text { Total } \\
\text { protein }\end{array}$} & \multirow[b]{2}{*}{ Albumin } & \multirow{2}{*}{$\begin{array}{l}\text { Alkaline } \\
\text { phosphatase }\end{array}$} & \multicolumn{2}{|c|}{ Bilirubin } & \multirow{2}{*}{$\begin{array}{l}\text { Total } \\
\text { retained } \\
\text { BSP }\end{array}$} & \multirow{2}{*}{$\underset{\text { BSP }}{\text { Conjugated }}$} \\
\hline & & & & & & Direct & Total & & \\
\hline
\end{tabular}

Viral Hepatitis

$\begin{array}{llll}\text { E.V. } & 31 & \text { F } & 6.5 \\ \text { B.T. } & 25 & \text { F } & 7.2 \\ \text { F.S. } & 24 & \text { M } & 6.6 \\ \text { M.H. } & 30 & \text { F } & 9.2 \\ \text { J.B. } & 24 & \text { F } & 7.1 \\ \text { E.D. } & 33 & \text { M } & 8.3 \\ \text { H.I. } & 40 & \text { F } & 7.7 \\ \text { E.G. } & 62 & \text { F } & 6.5 \\ \text { G.R. } & 32 & \text { M } & 6.4 \\ \text { M.B. } & \mathbf{5 8} & \text { F } & 8.0\end{array}$

Portal Cirrhosis

W.P. $\quad 54$

J.M. $\quad 70$

A.J. $\quad 59$

H.B. 52

D.B. 47

H.B. 49

P.J. $\quad 49$

J.K. $\quad 80$

$\begin{array}{ll}\text { M.C. } & 62 \\ \text { B.V. } & 43\end{array}$

$\begin{array}{ll}\text { B.V. } & 43 \\ \text { E. } & 43\end{array}$

M.D. $\quad 78$

P.D. $\quad 39$

$\begin{array}{ll}\text { C.C. } & 58 \\ \text { F.G. } & 42\end{array}$

H.C. $\quad 60$

J.M. $\quad 60$

P.B. 43

$\begin{array}{ll}\text { J.S. } & 41 \\ \text { J.V. } & 45\end{array}$

G.C. $\quad 58$

P.S. $\quad 55$

H.C. 16

A.D. $\quad 49$

M.W. $\quad 58$

J.D. $\quad 48$

H.G. $\quad 49$

L.B. $\quad 56$

$\begin{array}{ll}\text { T.W. } & 40 \\ \text { A.D } & 40\end{array}$

$\begin{array}{ll}\text { A.D. } & 40 \\ \text { R.G. } & 60\end{array}$

J.M. 63

\begin{tabular}{ll} 
M & 7.1 \\
M & 5.7 \\
M & 8.8 \\
M & 6.9 \\
F & 7.2 \\
M & 7.7 \\
M & 7.2 \\
F & 7.8 \\
M & 5.3 \\
M & 4.4 \\
F & 6.9 \\
M & 6.8 \\
F & 6.4 \\
M & 7.4 \\
F & 5.3 \\
M & 7.2 \\
F & 6.3 \\
M & 6.7 \\
F & 8.7 \\
M & 5.7 \\
M & 8.3 \\
F & 6.3 \\
F & 8.0 \\
F & 6.2 \\
M & 6.4 \\
F & 8.4 \\
M & 5.9 \\
F & 5.6 \\
F & 7.8 \\
F & 7.2 \\
F & 7.0 \\
F & 5.8 \\
M & 6.9 \\
& \\
\hline
\end{tabular}

$\begin{array}{rr}1.2 & 10.6 \\ 3.6 & 3.0 \\ 3.1 & 9.0 \\ 2.2 & 11.2 \\ 3.5 & 10.2 \\ 3.5 & 5.0 \\ 3.3 & 8.0 \\ 4.0 & 13.0 \\ 3.2 & 9.0 \\ 3.1 & 5.0\end{array}$

6.0
6.1
0.9
4.7
8.1
0.8
2.2
7.3
7.3
9.2

6.0

4.7

0.8

7.3

Mean

Standard error of mean

5.3

1.0

15.0
1.9
9.3
15.6
2.0
5.5
20.8
12.3
16.8

11.1
2.0

$0.1 \quad 0.7$

$\begin{array}{ll}1.1 & 1.6 \\ 0.1 & 1.0\end{array}$

$0.06 \quad 0.1$

0.3

0.2

0.1

1.2

0.2
0.02

0.7

0.3

0.1

0.6

2.3
0.4

0.06

0.1

0.4

5.0
10.0

1.5
0.2

0.2
2.2

2.8

1.6

2.8

0.6

0.6

1.5
9.0

9.0

0.5
2.8

1.2
0.6

0.3

3.0

0.6

0.04

1.9

0.7

0.4

1.5

5.0

0.4

0.4

1.2

13.4

3.0

0.8

6.8

7.7

5.8

4.5

2.0

1.0

5.1
18.5

10.3

3.7

1.1

6.7

1.5

3.8

Mean

0.4

1.0

$\begin{array}{rr}44 & 8 \\ 47 & 9 \\ 51 & 7 \\ 54 & 4 \\ 55 & 15 \\ 58 & 0 \\ 61 & 12 \\ 65 & 8 \\ 67 & 9 \\ 62 & 8 \\ 56.4 & 8.0 \\ 2.4 & 2.3\end{array}$

Standard error of mean 
TABLE II

Results of liver function tests in patients with extrahepatic and intrahepatic obstruction

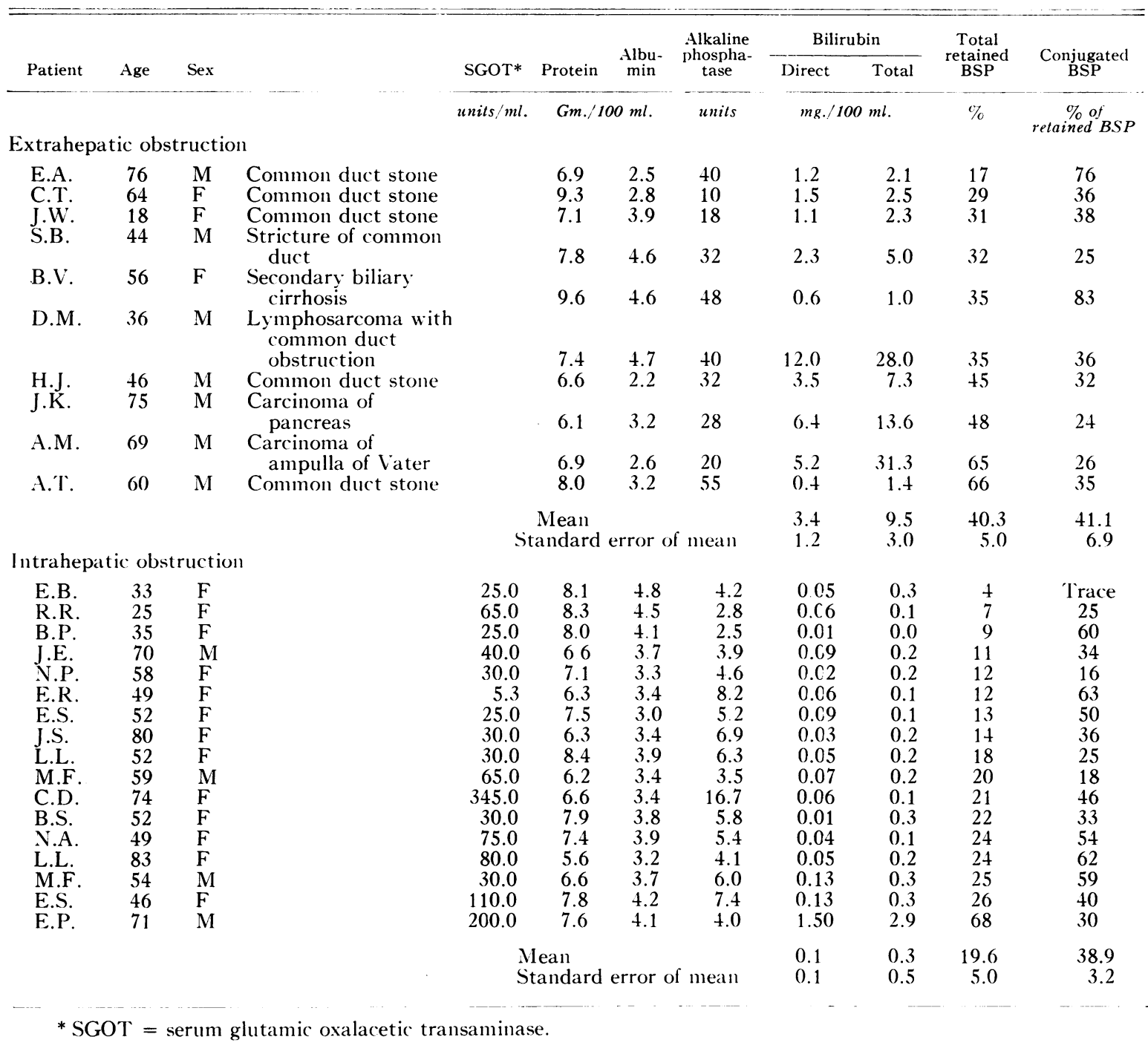

(38.9 \pm 3.2 per cent) was in the conjugated form. A rise in serum bilirubin concentration occurred in only one of the 17 subjects and a rise in serum alkaline phosphatase levels in two. Only seven of the subjects showed an elevation in serum glutamic oxalacetic transaminase levels.

\section{Statistical significance of differences}

Although the percentage of conjugated dye was significantly higher in the cirrhotic subjects than in the patients with viral hepatitis $(p<0.001)$, the mean difference between the two groups was comparatively small. The percentage of conjugate in the groups with extrahepatic and intrahepatic obstruction did not differ significantly $(p=0.7)$. The percentages in both of these groups, however, were approximately five times greater than the percentage of conjugates in the group with hepatitis and twice as high as that found in cirrhosis. Both these differences were highly significant (p) $<0.001)$.

Renal excretion of BSP and BSP metabolites (Table III)

The normal subjects excreted small amounts of dye into the urine. In patients with BSP re- 
tention induced by hepatitis, cirrhosis or obstruction the excretion of total BSP in the urine was five to 10 times greater than normal. The percentages of conjugated dye in the urine of each group of subjects, however, were not remarkably different and could not serve to differentiate the various disease states from each other or from the normal. In all groups a higher percentage of conjugated BSP was found in the urine than in the serum.

\section{DISCUSSION}

Several investigators $(18,19)$ have noted a time lag between the uptake of BSP by the liver and its eventual secretion into the bile and suggested that clearance of the dye by the liver involves two independent processes, uptake and secretion. The demonstration of conjugates of BSP (7-11) extends this scheme to include uptake, conjugation and secretion. Whether conjugation is the rate-limiting factor in uptake or secretion or whether it represents an intermediary process is not known. Impaired clearance of BSP could result from interference with any one or any combination of these processes.

Since the retained BSP is primarily in the unconjugated form in viral hepatitis, the defect may be either in the mechanism for the uptake or the conjugation of the dye, or both. Because such small amounts of the dye are conjugated to the form normally available for secretion, secretory function could not be evaluated under these circumstances. Subjects with cirrhosis also demonstrated a defect in uptake or conjugation of BSP. The somewhat elevated percentage of circulating metabolites found in these patients may indicate partial impairment of the secretory mechanism.

TABLE III

Appearance of sulfobromophthalein in urine two hours after injection of dye ( $5 \mathrm{mg}$. per $\mathrm{Kg}$. body weight)

\begin{tabular}{|c|c|c|c|}
\hline Group & $\begin{array}{l}\text { No. of } \\
\text { subjects }\end{array}$ & $\begin{array}{l}\text { Total } \\
\text { BSP }\end{array}$ & $\begin{array}{c}\text { Conjugated } \\
\text { BSP }\end{array}$ \\
\hline $\begin{array}{l}\text { Normal } \\
\text { Hepatitis } \\
\text { Cirrhosis }\end{array}$ & $\begin{array}{l}5 \\
5 \\
8\end{array}$ & $\begin{array}{r}m g . / 100 \mathrm{ml} . \\
2.7 \pm 1.1 \\
26.2 \pm 5.1 \\
21.1 \pm 6.5\end{array}$ & $\begin{array}{c}\% \\
72.0 \pm 13.8 \\
52.4 \pm 4.5 \\
47.6 \pm 7.9\end{array}$ \\
\hline $\begin{array}{l}\text { Extrahepatic } \\
\text { obstruction } \\
\text { Intrahepatic }\end{array}$ & 4 & $13.5 \pm 5.6$ & $78.0 \pm 5.5$ \\
\hline obstruction & 4 & $11.8 \pm 2.6$ & $63.0 \pm 7.0$ \\
\hline
\end{tabular}

Intrahepatic cholestasis may occur in fatty liver and florid cirrhosis as a result of strangulation of the bile ducts by scar tissue or inflammatory exudate (20). The high percentage of circulating conjugates in the subjects with obstruction of the common bile duct indicates that in this group the mechanisms for uptake and conjugation were functioning but that secretion was impaired. The moderate retention of free dye in these patients could result 1) directly from some impairment of the mechanism of uptake or conjugation, or 2) indirectly from impaired secretion resulting in trapping of large amounts of BSP conjugates in the liver, which in turn might cause product inhibition of the conjugating system. Methyltestosterone is known to cause hepatic dysfunction characterized by BSP retention, hyperbilirubinemia, hyperphosphatasemia and cholestasis $(21,22)$. The high percentage of BSP metabolites in the subjects treated with methyltestosterone suggests that the secretory mechanism is the site of the primary defect responsible for BSP retention. In recent studies of BSP clearance rates, similar conclusions have been suggested (23). In physical obstruction an increase in the circulating level of other substances normally excreted by the liver would be expected. Although this was true in patients with obstruction of the common bile duct, in the subjects treated with methyltestosterone, an elevation of BSP metabolites was apparent long before any rise in serum bilirubin or alkaline phosphatase became evident. This preferential appearance could be entirely a concentration effect. On the other hand, it does suggest that secretion at the cellular level may involve metabolic processes, some of which are specifically inhibited by the steroid, and that this inhibition produces a "metabolic" obstruction.

Determination of BSP and its conjugates may aid in distinguishing hepatic function disorders involving disturbances of uptake and conjugation from those involving secretion or regurgitation of BSP. In the presence of jaundice total BSP retention is almost invariably demonstrable. For this reason it has been suggested that measurement of retention of the dye where hyperbilirubinemia exists contributes little to the evaluation of liver function (24). Differentiation of hepatic function by measurement of the BSP me- 
tabolites, however, was possible in the presence or absence of hyperbilirubinemia. Furthermore, the differentiation was still possible in severe liver disease where the ratio of conjugated to free bilirubin proved of little value.

In the subjects given methyltestosterone, BSP retention proved more sensitive than serum bilirubin and serum glutamic oxalacetic transaminase levels in reflecting hepatic dysfunction, and the percentage of BSP conjugates was more sensitive than the serum alkaline phosphatase level in indicating secretory impairment of the liver cell. The sensitivity of the BSP test may depend on administration of large amounts of the dye, sufficient to load the various systems involved in its metabolism. This loading may emphasize slight hepatic functional defects which are not reflected by changes in serum bilirubin and alkaline phos-. phatase levels. Since BSP is an exogenous substance, alteration of serum levels by its endogenous production, such as occurs with bilirubin, is not a complicating factor. In addition, BSP and bilirubin may reflect different functions of the liver: mercaptide synthesis and secretion by BSP and glucuronide and sulfate formation by bilirubin. The BSP test becomes in part a measure of a specific biochemical reaction in the liver. Under certain circumstances this reaction may be specifically inhibited while other liver functions proceed. ${ }^{4}$

The percentage of conjugated dye in the urine was usually higher than the percentage in the serum of the same subject. Apparently the BSP metabolites are preferentially excreted in the urine, or they may be synthesized by the kidney. The latter possibility is supported by the demonstration of BSP conjugates in the urine of hepatectomized dogs (25).

\section{SUMMARY}

The levels of free and conjugated sulfobromophthalein (BSP) were determined in sera and

4 Through the courtesy of Dr. Barbara Billing (London, England), Dr. Leon Schiff (Cincinnati, Ohio), Dr. Owen C. Peck (Palo Alto, California) and Dr. Charbonnier (Paris, France), we had the opportunity of studying serum samples from three patients, all of which failed to show BSP conjugate. In all three specimens direct bilirubin was elevated, indicating formation of bilirubin glucuronide. urine from normal subjects and patients with hepatic dysfunction. The results showed that normal subjects conjugate and secrete BSP rapidly; only trace amounts of BSP and BSP metabolites are present in the serum 45 minutes after intravenous injection of a standard dose of the dye. Patients with viral hepatitis and cirrhosis conjugate BSP poorly and retain large amounts of unconjugated dye. Patients with impaired liver function caused by methyltestosterone and extrahepatic biliary obstruction conjugate the dye and accumulate large amounts in the serum. This accumulation was noted before changes in serum bilirubin, alkaline phosphatase and glutamic oxalacetic transaminase were evident. The measurement of the BSP metabolites appears sensitive for differentiating liver defects in uptake and conjugation from those affecting intracellular or extracellular obstruction.

Urinary BSP was mainly in the conjugated form. The percentages of conjugated dye in the urine of each group of subjects were not remarkably different and could not serve to differentiate the various disease states from the normal.

\section{REFERENCES}

1. O'Leary, P. A., Greene, C. H., and Rowntree, L. G. Diseases of the liver; various types of syphilis of liver with reference to tests for hepatic function. Arch. intern. Med. 1929, 44, 155.

2. MacDonald, D. Some observations on the disappearance of bromsulfalein dye from the blood; its relation to liver function (preliminary report). Canad. med. Ass. J. 1938, 39, 556.

3. MacDonald, D. A practical and clinical test for liver reserve. Surg. Gynec. Obstet. 1939, 69, 70.

4. Mateer, J. G., Baltz, J. I., Marion, D. F., and MacMillan, J. M. Liver function tests; a general evaluation of liver function tests, and an appraisal of the comparative sensitivity and reliability of the newer tests, with particular emphasis on the cephalin-cholesterol flocculation test, the intravenous hippuric acid test, and an improved bromsulfalein test with a new normal standard. J. Amer. med. Ass. 1943, 121, 723.

5. Rosenthal, S. M., and White, E. C. Clinical application of the bromsulphalein test for hepatic function. J. Amer. med Ass. 1925, 84, 1112.

6. Rosenthal, S. M., and White, E. C. Studies in hepatic function. VI. A. The pharmacological behavior of certain phthalein dyes. B. The value of selected phthalein compounds in the estimation 
of hepatic function. J. Pharmacol. exp. Ther. 1924, 24, 265.

7. Grodsky, G. M., Carbone, J. V., and Fanska, R. Metabolism of sulphobromophthalein. Nature (Lond.) 1959, 193, 469.

8. Brauer, R. W., Krebs, J. S., and Pessotti, R. L. Bromsulfonphthalein as a tool for study of liver physiology (abstract). Fed. Proc. 1950, 9, 259.

9. Krebs, J. S., and Brauer, R. W. Metabolism of sulfobromophthalein sodium (BSP) in the rat. Amer. J. Physiol. 1958, 194, 37.

10. Combes, B.. Biliary excretion by the rat of bromsulfalein as a conjugate of glycine and glutamic acid. Science 1959, 129, 388.

11. Meltzer, J. I., Wheeler, H. O., and Cranston, W. I. Metabolism of sulfobromophthalein sodium (BSP) in dog and man. Proc. Soc. exp. Biol. (N. Y.) 1959, 100, 174.

12. Grodsky, G. M., Carbone, J. V., and Fanska, R. Identification of metabolites of sulfobromophthalein. J. clin. Invest. 1959, 38, 1981.

13. Reinhold, J. G. Total protein, albumin and globulin in Standard Methods of Clinical Chemistry, M. Reiner, Ed. New York, Academic Press Inc., 1953, vol. 1, p. 88.

14. Shinowara, G. Y., Jones, L. M., and Reinhart, H. L. Estimation of serum inorganic phosphate and "acid" and "alkaline" phosphatase activity. J. biol. Chem. 1942, 142, 921.

15. Malloy, H. T., and Evelyn, K. A. Determination of bilirubin with photoelectric colorimeter. J. biol. Chem. 1937, 119, 481.
16. Gaebler, O. H. Determination of bromsulphalein in normal, turbid, hemolyzed or icteric serums. Amer. J. clin. Path. 1945, 15, 452.

17. Karmen, A., Wroblewski, F., and LaDue, J. S. Transaminase activity in human blood. J. clin. Invest. 1955, 34, 126.

18. Cantarow, A., and Wirts, C. W. Excretion of bromsulfalein in the bile. Proc. Soc. exp. Biol. (N. Y.) 1941, 47, 252.

19. Brauer, R. W., Pessotti, R. L., and Krebs, J. S. The distribution and excretion of $S^{35}$-labeled sulfobromophthalein-sodium administered to dogs by continuous infusion. J. clin. Invest. 1955, 34, 35.

20. Popper, H., and Schaffner, F. Liver: Structure and Function. New York, McGraw-Hill (Blakiston Div.), 1957, p. 197.

21. Werner, S. C., Hanger, F. M., and Kritzler, R. A. Jaundice during methyl testosterone therapy. Amer. J. Med. 1950, 8, 325.

22. Almaden, P. J., and Ross, S. W. Jaundice due to methyl testosterone therapy. Ann. intern. Med. 1954, 40, 146.

23. Heaney, R. P., and Whedon, G. D. Impairment of hepatic bromsulphalein clearance by two 17-substituted testosterones. J. Lab. clin. Med. 1958, 52, 169.

24. Snell, A. M., and Magath, T. B. The use and interpretation of tests for liver function. J. Amer. med. Ass. 1938, 110, 167.

25. Rosenau, W., Carbone, J. V., and Grodsky, G. M. Metabolism of sulfobromophthalein in the hepatectomized and the hepatectomized-nephrectomized dog. In preparation. 